\title{
BMJ Open Dietary protein-to-carbohydrate ratio and added sugar as determinants of excessive gestational weight gain: a prospective cohort study
}

\author{
Ekaterina Maslova, ${ }^{1}$ Thorhallur I Halldorsson, ${ }^{1,2,3}$ Arne Astrup, ${ }^{4}$ Sjurdur F Olsen ${ }^{1,5}$
}

To cite: Maslova $\mathrm{E}$, Halldorsson TI, Astrup A, et al. Dietary protein-tocarbohydrate ratio and added sugar as determinants of excessive gestational weight gain: a prospective cohort study. BMJ Open 2015;5: e005839. doi:10.1136/ bmjopen-2014-005839

- Prepublication history and additional material is available. To view please visit the journal (http://dx.doi.org/ 10.1136/bmjopen-2014005839).

Received 2 June 2014 Revised 9 January 2015 Accepted 12 January 2015

CrossMark

For numbered affiliations see end of article.

Correspondence to Dr Ekaterina Maslova; kmv@ssi.dk

\section{ABSTRACT}

Objective: To examine the relation between the protein:carbohydrate $(\mathrm{P} / \mathrm{C})$ ratio and added sugar intake in pregnancy and gestational weight gain (GWG).

Design: A prebirth cohort including 103119 pregnancies enrolled between 1996 and 2003.

Setting: All women in Denmark were eligible to participate if they spoke Danish and were planning to carry to term. The pregnant women were recruited and enrolled during their first antenatal visit (6-10 weeks of gestation).

Participants: Participants included women with liveborn singletons and complete data on dietary intake and GWG, leaving 46262 women for the analysis.

Exposure: Macronutrient intake was quantified using a validated food frequency questionnaire administered in the 25th week of gestation. The P/C ratio and added sugar intake were examined in quintiles.

Primary outcome measures: GWG was based on self-reported weight in gestational weeks 12 and 30 and defined as gain in $\mathrm{g} /$ week. We used multivariable linear regression, including adjusting for prepregnancy body mass index, to calculate relative change in GWG and $95 \% \mathrm{Cl}$.

Results: Average GWG was 471(224) g/week. The adjusted weight gain was $16 \mathrm{~g} /$ week lower $(95 \% \mathrm{Cl}$ 9 to 22, $p$ for trend $<0.001$ ) in the highest (Q5) versus lowest (Q1) quintile of the $P / C$ ratio $(\sim 3 \%$ average reduction across the entire pregnancy). Weight gain for those with $>20 \% \mathrm{E}$ vs $<12 \% \mathrm{E}$ from protein was $36 \mathrm{~g} /$ week lower $(95 \% \mathrm{Cl} 20$ to 53 , p for trend $<0.0001 ; \sim 8 \%$ average reduction). A high P/C ratio was inversely related to intake of added sugars. Added sugar consumption was strongly associated with GWG (Q5 vs Q1: $34,95 \% \mathrm{Cl} 28$ to $40 \mathrm{~g} /$ week, $p$ for trend $<0.0001$ ).

Conclusions: $A$ high $P / C$ ratio was associated with reduced GWG. This association appeared to be partly driven by a decrease in intake of added sugar. These results are consistent with randomised trials in non-pregnant participants. A dietary intervention targeting an increased $\mathrm{P} / \mathrm{C}$ ratio with emphasis on reducing added sugar can contribute to reducing excessive GWG.

\section{Strengths and limitations of this study}

- The study finding of a high protein:carbohydrate ratio as an important determinant of reduced gestational weight gain is largely consistent with trial data in non-pregnant populations.

- The study highlights the relation between dietary factors and gestational weight gain among women with different pre-pregnancy body mass index.

- The strengths of this study are the large study population, detailed dietary assessment and extensive data on covariates.

- The main limitation is plausible misreporting of the diet and gestational weight gain in primarily obese women.

\section{INTRODUCTION}

Excessive gestational weight gain (GWG) has been associated with adverse perinatal and postnatal outcomes, including gestational diabetes, ${ }^{1}{ }^{2}$ hypertension, ${ }^{2}$ macrosomia ${ }^{3}$ and increased overweight in the offspring. ${ }^{4} 5$ The Institute of Medicine (IOM) has established guidelines for healthy pregnancy weight gains based on optimal maternal and offspring outcomes. ${ }^{6}$ Despite available guidelines, $30-60 \%$ of women still put on excessive weight during pregnancy. ${ }^{7-9}$ Understanding behavioural and lifestyle determinants of weight gain (and relative loss) to optimise weight gain during pregnancy is crucial, especially in the light of the growing obesity epidemic.

Randomised and non-randomised interventions to impact GWG through improvements in dietary and/or physical activity habits have shown no ${ }^{10-14}$ or marginal ${ }^{15} 16$ effects; larger effect sizes were observed among subgroups of obese $\mathrm{e}^{17-19}$ and lowincome women. ${ }^{20}$ Improved dietary habits in the intervention groups did not always translate to a change in GWG. ${ }^{10}{ }^{11}{ }^{13}$ While these 
studies to optimise GWG are of importance, the relative contribution of the individual intervention components cannot be teased apart. Insight into specific and targeted nutritional advice is therefore of great interest and may be more directly transferable into public recommendations. Observational studies examining dietary predictors of GWG found that high protein and fat were related to increased GWG or the odds of excess GWG. $^{8} 921$ Associations for carbohydrates with GWG were less consistent. ${ }^{8}$ Foods rich in protein and carbohydrates, for example, dairy ${ }^{8}{ }^{9}$ and sweets ${ }^{8}$ have also been associated with increased GWG.

High-protein diets have been shown to decrease weight and lead to better weight maintenance in nonpregnant populations, often obtained by a reduction in carbohydrates. ${ }^{22-26}$ However, the role of protein intake in relation to GWG has been less studied. A Cochrane review found high-protein supplements in pregnancy to be associated with a marginal increase in GWG, but the importance of high-protein intake at the expense of carbohydrates for GWG is unclear. ${ }^{27}$

Long-term effects assessed by longitudinal observational studies in non-pregnant populations have been hampered by methodological limitations, for example, small weight gains over many years. The weight gain over a short time during pregnancy in a large cohort with detailed dietary data provides an opportunity to overcome these problems, but studies in pregnant populations have been few and have not examined the protein-carbohydrate relation in detail. We therefore evaluated the association of the protein:carbohydrate $(\mathrm{P} / \mathrm{C})$ ratio and protein substituted for carbohydrate in pregnancy with GWG in the prospective Danish National Birth Cohort.

\section{METHODS}

\section{Study population}

Collection of maternal lifestyle and health information during pregnancy in the Danish National Birth Cohort (DNBC) has previously been described in detail. ${ }^{28}{ }^{28 a} \mathrm{In}$ brief, 103119 pregnancies from all over Denmark were recruited from January 1996 until October 2002, corresponding to approximately $35 \%$ of all deliveries in Denmark during the recruitment period. ${ }^{28}{ }^{28 a}$ Eligible for recruitment were all pregnant women who were fluent in Danish and living in Denmark. Women were enrolled at the first antenatal visit to the general practitioner around weeks $6-10$ of gestation and were interviewed twice during pregnancy over the telephone around weeks 12 and 30 of gestation. Maternal health and birth records were also extracted through registry linkages.

Mothers provided written informed consent for themselves and on behalf of their children.

\section{Dietary assessment}

A food-frequency questionnaire $(\mathrm{FFQ})$ was mailed to the women around week 25 of gestation covering intake during the previous 4 weeks. This time point was originally chosen because diet was assumed to be more stable in midpregnancy compared with early pregnancy and because most pregnancy outcomes of interest, for example, preterm delivery, had not yet occurred. ${ }^{28}$ Food items were calculated into grams per day using assumptions on standard portion sizes, and nutrient intake was quantified using the National Food Institute's Food Composition Databank V.6.02 (http://www.foodcomp.dk). The FFQ has been validated against biomarkers of particular nutrients and 7-day weighed food diaries $(\mathrm{n}=88)$ with reasonable correlation (Spearman $\mathrm{r}=0.44$ ) observed between protein from food diaries and the FFQ. ${ }^{29} 30$

\section{Gestational weight gain}

Information on maternal weight was available from the two telephone interviews conducted during pregnancy. As a result, we used as outcome the rate of weight gain in grams per week from week 12 (first interview) to week 30 (second interview) of gestation. We therefore assumed that the weight gain would be, on average, similar in the missed gestational weeks in early and late pregnancy. Owing to some dispersion in the timing of the two interviews, weight gain for participants with $\leq 60$ or $>200$ days in between the two interviews $(10.7 \%)$ was recorded as missing to ensure a reasonable time period to register the weight change accurately.

\section{Cohort attrition}

Of the 103119 pregnancies registered in the cohort, 92653 were live-born singletons. In total, 68240 out of 92653 pregnancies had FFQ data with some $(n=6704)$ being recruited more than once in later pregnancies. To avoid intercorrelated observations, we restricted our analyses to first cohort pregnancy enrolment (independent of any prior children). Of the 61536 women, 325 were excluded due to implausible low $(<2500 \mathrm{~kJ})$ or high $(>25000 \mathrm{~kJ})$ energy intake. Of the 61211 remaining women, the outcome was missing for 14949 , leaving 46262 women available for analysis.

\section{Statistical analyses}

The mean and SD or percentages were used to describe normally distributed or dichotomous variables, respectively. All covariates were examined for potential outliers. Univariable and multivariable linear regression was used to examine the association between dietary intake and GWG. Assumptions of normality of model residuals were checked by visual inspection of histograms and $\mathrm{Q}-\mathrm{Q}$ plots. The $\mathrm{P} / \mathrm{C}$ ratio was transformed into $\mathrm{z}$-scores to allow for the examination of the effect of a 1 SD change in the exposure on GWG. In the protein substitution models, we examined a 1:1 kcal substitution for carbohydrates by including all energy-contributing nutrients, except for carbohydrates, in an isocaloric model. ${ }^{31}$ In such a model, the effect estimate can be interpreted as the effect of increasing intake of protein at the expense of carbohydrates while keeping calories constant. In our 
primary analyses, dietary variables were divided into quintiles to account for potential non-linearity. When testing for linear trend, the quintile variable was coded with the median dietary value in each quintile and entered as a continuous term in the regression model to calculate $p$ for trend. To examine the relation for more extreme categories of protein intake with GWG, we used low $(<12 \%)$ and high $(>20 \%)$ cut-off points based on the population distribution. In our adjusted models, we identified and selected a priori the following set of covariates: socioeconomic status (based on parental profession, including students and unemployed), maternal age, parity, maternal pre-pregnancy body mass index (BMI), maternal height, maternal smoking during pregnancy, civil status and total energy intake. Further adjustment for physical activity in pregnancy did not substantially change the effect estimates. Missing data did not exceed $1 \%$ for any of the covariates, and therefore any missing values were excluded from the analyses. In subgroup analyses, we examined the associations stratified by pre-pregnancy BMI (normal weight, overweight, obese).

All tests were two-sided, and we used a threshold of $\mathrm{p}<0.05$ to denote statistical significance. The analyses were performed using the Statistical Analyses System software (release V.9.3; SAS Institute, Cary, North Carolina, USA).

\section{RESULTS}

\section{Study population}

We examined the distribution of nutrient intake and sociodemographic characteristics across quintiles of the $\mathrm{P} / \mathrm{C}$ ratio among 46262 pregnant women eligible for this study (table 1). Protein, primarily animal protein and fat intake increased across quintiles of the $\mathrm{P} / \mathrm{C}$ ratio, while carbohydrates, primarily added sugars and fibre decreased. Pregnant women in the highest quintile of the $\mathrm{P} / \mathrm{C}$ ratio tended to be multiparous $(49 \%$ vs $44 \%$ ), have a BMI $\geq 25 \mathrm{~kg} / \mathrm{m}^{2}(32 \%$ vs $25 \%)$ and to be current smokers ( $15 \%$ vs $12 \%$ ). The mean (SD) GWG was 471 (224) $\mathrm{g}$ /week.

Pregnant women with outcome information but missing dietary data $(\mathrm{N}=14272)$ were less likely to be of high and medium proficiency (50\% vs $55 \%$ ), nulliparous $(44 \%$ vs $53 \%)$ and non-smokers $(68 \%$ vs $75 \%)$ compared with women with dietary data $(\mathrm{N}=46262)$. We found no substantial difference for marital status, maternal age, height, pre-pregnancy BMI or GWG between the two groups.

\section{$\mathrm{P} / \mathrm{C}$ ratio and protein intake and in relation to GWG}

The results for the multivariable linear regression analysis are shown in table 2. Adjusting for covariates led to minor attenuation of the effect estimates; adjustment for maternal age and pre-pregnancy BMI accounted for the majority of the attenuation. Pregnant women consuming in the highest (vs lowest) quintile $(\mathrm{Q})$ of the $\mathrm{P} / \mathrm{C}$ ratio had a lower rate of GWG (Q5 vs Q1: $-16 \mathrm{~g} /$ week, $95 \%$ CI -22 to $-9, p$ for trend $<0.0001)$. In other words, pregnant women consuming more protein (or less carbohydrates) gained less weight than women who consumed less protein (or more carbohydrates). Similarly, women who replaced more carbohydrates with protein gained 13 (95\% CI -20 to -7 , p for trend $<0.0001)$ grams less per gestational week compared with women in the lowest quintile. Protein intake $<12 \%$ of energy increased GWG while protein intake $>20 \%$ of energy reduced GWG. Comparing the two extreme intakes $(<12 \% \mathrm{E}$ vs $>20 \% \mathrm{E})$, we found an increase in GWG of $36 \mathrm{~g} /$ week (95\% CI 20 to 53). Stratifying on prepregnancy BMI generated similar results in normal weight and overweight women, though the results were slightly stronger in the latter (table 3). No associations with any of the exposures were present for obese women. Substitution for fat instead of carbohydrates yielded similar though slightly weaker results for the above analyses (data not shown). We also further adjusted for dietary factors that have been shown to influence weight gain in non-pregnant and pregnant populations (dietary fibre, milk intake, n-3 fatty acids).$^{82-34}$ Some of the effects of these nutrients on body weight may be mediated through non-energyrelated mechanisms such as satiety, and may therefore not be fully accounted for by adjusting for total energy. Adjustment for dietary fibre and milk intake strengthened the results, especially for the latter, while adjustment for $\mathrm{n}-3$ fatty acids attenuated the effect estimates (data not shown).

\section{Added sugar in relation to GWG}

We explored whether the $\mathrm{P} / \mathrm{C}$ ratio results were driven by a change in carbohydrates, specifically added sugar. Pregnant women with an intake of added sugar in the highest quintile $(89 \pm 26 \mathrm{~g} /$ day $)$ had a higher $\mathrm{GWG}$ rate when compared with women in the lowest quintile (19 $\pm 5 \mathrm{~g} /$ day; $34 \mathrm{~g} /$ week, $95 \%$ CI 28 to 40 ; table 4 ). Mutual adjustment for the $\mathrm{P} / \mathrm{C}$ ratio and added sugar attenuated the former but not the latter. When stratifying the women according to whether they were above or below the median intake of added sugar ( $41 \mathrm{~g} /$ day) and examining the relation between the $\mathrm{P} / \mathrm{C}$ ratio and $\mathrm{GWG}$, we found no association for those consuming added sugar $\geq 41 \mathrm{~g} /$ day. On the other hand, those below the median intake of added sugar had a lower mean GWG (Q5 vs Q1: $-12 \mathrm{~g} /$ week, $95 \%$ CI -22 to -2 , $p$ for trend 0.02 ).

\section{Secondary analyses}

In secondary analyses, we examined whether the source of protein was of importance by subdividing the protein into animal and vegetable protein; we found that the results were similar to the main analyses (see online supplementary table S1). Further subdivision of animal protein into protein from meat (red and white meat, including processed products), fish/fish products and 
Table 1 Maternal covariate distributions across quintiles of the P/C ratio in mid-pregnancy, N=46 262

\begin{tabular}{|c|c|c|c|c|c|}
\hline & \multicolumn{5}{|c|}{ Quintiles of the $\mathrm{P} / \mathrm{C}$ ratio in pregnancy } \\
\hline & 1 & 2 & 3 & 4 & 5 \\
\hline & $\begin{array}{l}\text { Per cent or } \\
\text { means (SD) }\end{array}$ & $\begin{array}{l}\text { Per cent or } \\
\text { means (SD) }\end{array}$ & $\begin{array}{l}\text { Per cent or } \\
\text { means (SD) }\end{array}$ & $\begin{array}{l}\text { Per cent or } \\
\text { means (SD) }\end{array}$ & $\begin{array}{l}\text { Per cent or } \\
\text { means (SD) }\end{array}$ \\
\hline $\mathrm{P} / \mathrm{C}$ ratio & $0.21 \pm 0.02$ & $0.25 \pm 0.01$ & $0.28 \pm 0.01$ & $0.31 \pm 0.01$ & $0.37 \pm 0.04$ \\
\hline GWG (g/week) & $482(226)$ & $477(215)$ & $471(217)$ & $467(223)$ & $458(239)$ \\
\hline Energy (kcal/day) & $2373(658)$ & $2427(622)$ & $2425(621)$ & $2410(621)$ & $2366(661)$ \\
\hline Protein intake $(\% E)^{*}$ & $13(2)$ & $15(1)$ & $15(1)$ & $16(2)$ & $18(2)$ \\
\hline Animal protein (\%E) & $7(1)$ & $9(1)$ & $10(1)$ & $11(1)$ & $13(2)$ \\
\hline Vegetable protein (\%E) & $5(1)$ & $5(1)$ & $5(1)$ & $5(1)$ & $4(1)$ \\
\hline Carbohydrate intake (\%E) & $61(5)$ & $57(5)$ & $55(5)$ & $53(4)$ & $49(5)$ \\
\hline Sugar (\%E) & $25(7)$ & $21(6)$ & $20(5)$ & $19(5)$ & $19(5)$ \\
\hline Added sugar (\%E) & $11(6)$ & $9(4)$ & $8(4)$ & $7(3)$ & $6(3)$ \\
\hline Fibre (g/day) & $27(10)$ & $28(9)$ & $27(9)$ & $26(9)$ & $22(9)$ \\
\hline Fat intake (\%E) & $28(6)$ & $30(6)$ & $31(6)$ & $32(6)$ & $34(6)$ \\
\hline Saturated fat (\%E) & $11(3)$ & $12(3)$ & $13(3)$ & $13(3)$ & $14(4)$ \\
\hline Monounsaturated fat (\%E) & $9(2)$ & $9(2)$ & $10(2)$ & $10(2)$ & $11(2)$ \\
\hline Polyunsaturated fat (\%E) & $4(1)$ & $5(1)$ & $5(1)^{\prime}$ & $5(1)^{\prime}$ & $5(1)^{\prime}$ \\
\hline Glycaemic Index & 76.3 (50.2) & $63.4(37.5)$ & $63.8(36.2)$ & $67.1(37.4)$ & $79.9(46.8)$ \\
\hline Maternal age (years) & $29.8(4.2)$ & $30.2(4.1)$ & $30.4(4.1)$ & $30.5(4.2)$ & $30.6(4.3)$ \\
\hline Primiparous & 56 & 53 & 53 & 52 & 51 \\
\hline \multicolumn{6}{|l|}{ Socioeconomic position } \\
\hline High-level proficiencies & 23 & 24 & 24 & 24 & 22 \\
\hline Medium-level proficiencies & 31 & 33 & 33 & 32 & 30 \\
\hline Skilled & 27 & 27 & 27 & 28 & 29 \\
\hline Student & 7 & 6 & 5 & 5 & 5 \\
\hline Unskilled & 11 & 9 & 10 & 10 & 12 \\
\hline Unemployed & 2 & 1 & 1 & 1 & 2 \\
\hline Married/cohabitating & 98 & 98 & 99 & 98 & 98 \\
\hline \multicolumn{6}{|l|}{ Pre-pregnancy BMI $\left(\mathrm{kg} / \mathrm{m}^{2}\right)$} \\
\hline$\geq 18.5$ & 5 & 5 & 4 & 4 & 4 \\
\hline $18.6-24.9$ & 70 & 70 & 70 & 69 & 64 \\
\hline $25-29.9$ & 18 & 18 & 19 & 20 & 22 \\
\hline$\geq 30$ & 7 & 7 & 7 & 8 & 10 \\
\hline \multicolumn{6}{|l|}{ Smoking in pregnancy } \\
\hline Non-smoker & 75 & 77 & 77 & 76 & 71 \\
\hline Occasional smoker & 13 & 13 & 13 & 13 & 14 \\
\hline Current smoker & 12 & 10 & 10 & 12 & 15 \\
\hline
\end{tabular}

${ }^{*}$ Energy-adjusted protein, means (SD): $75 \pm 8 ; 84 \pm 7 ; 90 \pm 7 ; 96 \pm 8$ and $105 \pm 11 \mathrm{~g} /$ day.

$\mathrm{BMI}$, body mass index; GWG, gestational weight gain; $\mathrm{P} / \mathrm{C}$ ratio, protein:carbohydrate ratio.

dairy (milk, cheese) showed lower GWG with high protein from meat and fish but not dairy products.

Glycaemic Index (GI) was directly but weakly associated with GWG (Q4 vs Q1: $6 \mathrm{~g} /$ week, $95 \%$ CI -1 to 13 ; see online supplementary table S2). This association was present for normal weight, but not overweight or obese women. Mutual adjustment for the $\mathrm{P} / \mathrm{C}$ ratio and GI did not change the results for either exposure.

Intake of sweets (primarily chocolate and mixed candy) was directly associated with GWG and this was true regardless of women's pre-pregnancy BMI (see online supplementary table S3).

\section{DISCUSSION}

In this study of 46262 pregnant women in the Danish National Birth Cohort, we found that a higher $\mathrm{P} / \mathrm{C}$ ratio and replacing carbohydrates with protein reduced GWG. These results were largely independent of the type of protein source and pre-pregnancy BMI. Instead, the association appeared to be driven more by the reduction in carbohydrates, specifically added sugar. Added sugar also modified the relation between the $\mathrm{P} / \mathrm{C}$ ratio and GWG in that only those with a low intake derived any benefit from a high $\mathrm{P} / \mathrm{C}$ ratio. In support of this, a high GI and intake of sweets increased GWG. Assuming a constant rate of GWG across pregnancy and a 40-week gestation, our results suggest, on average, a $0.6 \mathrm{~kg}$ (95\% CI 0.4 to 0.9$)$ lower weight gain among pregnant women consuming at a higher $\mathrm{P} / \mathrm{C}$ ratio (comparing Q5 $(0.37 \pm 0.04)$ to $\mathrm{Q} 1(0.21 \pm 0.02))$. For added sugar ( $89 \pm 26$ vs $19 \pm 5 \mathrm{~g} /$ day), this would correspond to a weight gain of $1.4 \mathrm{~kg}$ (95\% CI 1.1 to 1.6 ) during pregnancy. In an observational setting, we cannot determine 
Table 2 The association between the protein:carbohydrate ratio z-score and protein intake (substituted for carbohydrates ${ }^{*}$ ) in mid-pregnancy and gestational weight gain (g/week), $\mathrm{N}=46262$

\begin{tabular}{|c|c|c|c|c|}
\hline & \multicolumn{4}{|c|}{ Gestational weight gain (g/week) } \\
\hline & \multicolumn{2}{|l|}{ Crude (mean $\Delta, 95 \% \mathrm{Cl}$ ) } & \multicolumn{2}{|l|}{ Adjusted† (mean $\Delta, 95 \% \mathrm{Cl})$} \\
\hline Protein:carbohydrate ratio z-score & & $\mathrm{p}$ for trend $\ddagger$ & & $p$ for trend \\
\hline Q2 $(-0.5 \pm 0.1)$ & $-7(-13$ to -0$)$ & & $-6(-13$ to -0$)$ & \\
\hline Q3 $(-0.1 \pm 0.1)$ & $-13(-19$ to -6$)$ & & $-11(-18$ to -5$)$ & \\
\hline Q4 (0.4 00.2$)$ & $-16(-22$ to -9$)$ & & $-12(-19$ to -6$)$ & \\
\hline Q1 $(71 \pm 6) \S$ & 0 (reference) & $<0.0001$ & 0 (reference) & $<0.0001$ \\
\hline Q2 (83 \pm 2$)$ & $-9(-15$ to -2$)$ & & $-10(-17$ to -4$)$ & \\
\hline 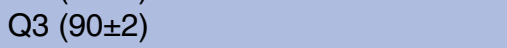 & $-6(-13$ to 0$)$ & & $-8(-14$ to -1$)$ & \\
\hline Q4 (96 \pm 2$)$ & $-12(-19$ to -5$)$ & & $-12(-18$ to -5$)$ & \\
\hline Q5 (109 \pm 7$)$ & $-16(-23$ to -9$)$ & & $-13(-20$ to -7$)$ & \\
\hline Low versus high protein $(\mathrm{N}=4733)$ & & $\mathrm{p}$ Value & & $\mathrm{p}$ Value \\
\hline$<12 \%$ vs $>20 \%$ & 39 (22 to 55$)$ & $<0.0001$ & $36(20$ to 53$)$ & $<0.0001$ \\
\hline \multicolumn{5}{|c|}{$\begin{array}{l}\text { *Isocaloric regression models including protein and fat while excluding carbohydrates. } \\
\text { †Adjusted for parental socioeconomic status, maternal age, parity, maternal pre-pregnancy body mass index, maternal height, maternal } \\
\text { smoking, civil status and total energy intake. } \\
\ddagger \text { Łp Value for trend using the quintile median. } \\
\S \text { Means } \pm S D \text {. Means } \pm S D \text { for protein are energy-adjusted. } \\
\text { |Additionally adjusted for total fat intake. }\end{array}$} \\
\hline
\end{tabular}

whether these are independent effects. Importantly, the changes in GWG observed in our study are comparable in magnitude with the changes found with increasing pre-pregnancy BMI, an important predictor of GWG, ${ }^{35}$ in our and other studies (overweight vs normal weight: $-17-26 \mathrm{~g} /$ week). ${ }^{36}$ Additionally, the reduction in GWG $(\sim 3-7 \%)$ is similar to long-term weight-loss trials in nonpregnant adults. $^{24} 37$

Table 3 The association between the protein:carbohydrate ratio z-score in mid-pregnancy and gestational weight gain ( $\mathrm{g} /$ week) stratified by maternal pre-pregnancy body mass index

\begin{tabular}{|c|c|c|c|c|}
\hline & \multicolumn{4}{|c|}{ Gestational weight gain (g/week) } \\
\hline & Crude (mean $\Delta, 95 \% \mathrm{Cl})$ & $p$ for trend* & Adjusted†(mean $\Delta, 95 \% \mathrm{Cl})$ & $p$ for trend \\
\hline \multicolumn{5}{|c|}{ Normal weight women $(\mathrm{N}=31633)$} \\
\hline Q1 $(-1.3 \pm 0.4) \ddagger$ & 0 (reference) & $<0.0001$ & 0 (reference) & $<0.0001$ \\
\hline Q2 (-0.5 \pm 0.1$)$ & $-8(-15$ to -2$)$ & & $-9(-15$ to -2$)$ & \\
\hline Q3 $(-0.1 \pm 0.1)$ & $-12(-18$ to -5$)$ & & $-11(-18$ to -4$)$ & \\
\hline Q4 $(0.4 \pm 0.2)$ & $-17(-23$ to -10$)$ & & $-15(-22$ to -8$)$ & \\
\hline Q5 (1.4 \pm 0.8$)$ & $-17(-24$ to -10$)$ & & $-15(-21$ to -8$)$ & \\
\hline \multicolumn{5}{|c|}{ Overweight women $(\mathrm{N}=8956)$} \\
\hline Q1 (-1.3 \pm 0.4$)$ & 0 (reference) & $<0.0001$ & 0 (reference) & 0.001 \\
\hline Q2 $(-0.5 \pm 0.1)$ & $-8(-25$ to 9$)$ & & $-6(-23$ to 11$)$ & \\
\hline Q3 $(-0.1 \pm 0.1)$ & $-21(-38$ to -4$)$ & & $-19(-36$ to -2$)$ & \\
\hline Q4 $(0.4 \pm 0.2)$ & $-24(-41$ to -8$)$ & & $-19(-36$ to -3$)$ & \\
\hline Q5 (1.5 \pm 0.7$)$ & $-34(-50$ to -17$)$ & & $-26(-43$ to -10$)$ & \\
\hline \multicolumn{5}{|c|}{ Obese women $(\mathrm{N}=3667)$} \\
\hline Q1 $(-1.3 \pm 0.4)$ & 0 (reference) & 0.81 & 0 (reference) & 0.57 \\
\hline Q2 $(-0.5 \pm 0.1)$ & $17(-17$ to 52$)$ & & $18(-16$ to 53$)$ & \\
\hline Q3 $(-0.0 \pm 0.1)$ & $11(-23$ to 45$)$ & & $13(-21$ to 47$)$ & \\
\hline Q4 $(0.4 \pm 0.2)$ & $24(-10$ to 58$)$ & & 25 (-9 to 58$)$ & \\
\hline Q5 $(1.5 \pm 0.8)$ & $5(-26$ to 37$)$ & & $11(-21$ to 43$)$ & \\
\hline
\end{tabular}

${ }^{*} \mathrm{p}$ Value for trend using the quintile median.

†Adjusted for parental socioeconomic status, maternal age, parity, maternal height, maternal smoking, civil status and total energy intake. $\ddagger$ Means \pm SD. 
Table 4 The association between added sugar intake during pregnancy and gestational weight gain ( $\mathrm{g} / \mathrm{week}$ ) and effect modification of the protein:carbohydrate ratio z-score above and below the median intake of added sugar

\section{Gestational weight gain ( $g /$ week)}

Crude (mean $\Delta, 95 \% \mathrm{Cl}) \quad \mathrm{p}$ for trend ${ }^{\star} \quad$ Adjustedt $(\operatorname{mean} \Delta, 95 \% \mathrm{Cl}) \quad \mathrm{p}$ for trend

\begin{tabular}{|c|c|c|c|}
\hline \multicolumn{4}{|l|}{$\begin{array}{l}\text { Added sugar } \\
N=46262\end{array}$} \\
\hline Q1 $(19 \pm 5) \ddagger$ & 0 (reference) & $<0.0001$ & 0 (reference) \\
\hline Q2 (31 \pm 3$)$ & 23 (16 to 29$)$ & & 17 (11 to 23$)$ \\
\hline Q3 $(41 \pm 3)$ & 29 (22 to 35$)$ & & 23 (16 to 29$)$ \\
\hline Q4 $(54 \pm 5)$ & 35 (29 to 41$)$ & & 27 (21 to 33 ) \\
\hline Q5 $(89 \pm 26)$ & 40 (33 to 46$)$ & & 34 (28 to 40$)$ \\
\hline
\end{tabular}

Protein:carbohydrate ratio

z-score (added sugar $\geq 41 \mathrm{~g} /$ day)

$\mathrm{N}=23131$

Q1 $(-1.3 \pm 0.4)$

Q2 $(-0.5 \pm 0.1)$

Q3 $(-0.1 \pm 0.1)$

Q4 $(0.4 \pm 0.2)$

Q5 (1.3 \pm 0.5$)$

23 (16 to 29$)$

29 (22 to 35$)$

40 (33 to 46$)$

Protein:carbohydrate ratio

z-score (added sugar < 41 g/day)

$\mathrm{N}=23131$

Q1 $(-1.2 \pm 0.3)$

Q2 $(-0.5 \pm 0.1)$

Q3 $(-0.1 \pm 0.1)$

Q4 $(0.4 \pm 0.2)$

Q5 (1.5 \pm 0.8$)$

$$
\begin{aligned}
& 0 \text { (reference) } \\
& -4(-12 \text { to } 4) \\
& -7(-15 \text { to } 1) \\
& -8(-17 \text { to } 1) \\
& -9(-19 \text { to } 1)
\end{aligned}
$$

0 (reference)

-5 ( -12 to 3$)$

-6 ( -15 to 2$)$

$-7(-16$ to 1$)$

$-2(-12$ to 8$)$

$<0.0001$

0 (reference)

$-13(-24$ to -1$)$

$-14(-25$ to -3$)$

$-21(-32$ to -11$)$

-4 ( -16 to 7$)$

$-10(-21$ to 1$)$

-8 ( -19 to 2$)$

$-12(-22$ to -2$)$
$<0.0001$

p for interaction $<0.0001$

0.02

${ }^{*} p$ Value for trend using the quintile median.

†Adjusted for parental socioeconomic status, maternal age, parity, maternal pre-pregnancy body mass index, maternal height, maternal smoking, civil status and total energy intake.

$\ddagger$ Means $\pm S D$. Means \pm SD for added sugar are energy-adjusted.

Low-carbohydrate diets have been effective in promoting weight loss in non-pregnant populations, ${ }^{22}$ but this is the first study to suggest that these types of diets could be considered in pregnant populations in order to reduce excessive GWG, especially in high-risk women entering their pregnancy already overweight or obese. The present study suggests that just modest reductions in carbohydrates and a slight increase in protein may have the potential to reduce GWG to a clinically relevant degree. We also stipulate that pregnancy offers a 9-month simplified model in which to examine dietary and lifestyle determinants of weight gain, as opposed to weight changes ongoing over many years in nonpregnant individuals.

Our results are in some agreement with past studies. A study in 495 Icelandic women found that those with excess GWG had a higher intake of carbohydrates in $\mathrm{g} /$ day. ${ }^{8}$ Additionally, women consuming more sweets were twice as likely to gain excessive weight during pregnancy according to the IOM recommendations, ${ }^{38}$ but no association was detected for either protein or added sugar in this relatively smaller study. However, macronutrient intakes were quantified in the 32-35 weeks of gestation and could have reflected dietary changes in women on track to excessive weight gain. Two US studies found the opposite results with high-protein consumption associated with an increase in $\mathrm{GWG}^{9}{ }^{91}$ although results in only one study were statistically significant. ${ }^{21}$ Maternal intake of milk and dairy was found to be related to excessive GWG in two study populations; ${ }^{8} 9$ also, in the DNBC, GWG increased univariately across categories of milk consumption. ${ }^{39}$ In this study, we examined substitution of subtypes of protein, including protein from dairy products, for carbohydrates and found no associations with GWG. However, adjusting for milk intake strengthened the inverse association of the $\mathrm{P} / \mathrm{C}$ ratio with GWG. This could possibly reflect the postulated insulin-like growth factor-1-mediated growthpromoting effect of consuming dairy products in pregnancy, ${ }^{39}$ which may in turn impact GWG, and adjustment for energy-dense components, such as lactose and fat, in milk, which may contribute to weight gain. While higher protein intake may be beneficial for GWG, it could lead to adverse programming in the offspring. ${ }^{40}$ Whether any programming effects are mediated by GWG, or are independent thereof, needs to be the focus of future studies.

We observed some of our strongest associations with added sugar and sweets, suggesting that the reduction in carbohydrates rather than an increase in protein may be 
a stronger driver in reducing GWG. In a secondary and supporting analysis, we also found a weak increase in GWG with higher GI, which was stronger for normal weight women. While GI and glycaemic load (GL) were not found to be associated with GWG in two previous studies that did not stratify on pre-pregnancy BMI, ${ }^{7}$ a recent study from the DNBC showed that GL increased GWG in normal weight and overweight women. ${ }^{41}$

The present results could be explained by physiological responses to increased protein and reduced carbohydrate intake. Higher consumption of protein has been shown to increase satiety, ${ }^{42}$ possibly by increasing satiety-inducing hormones such as peptide YY (PYY) and glucagon-like peptide- $1^{43}$ and repressing hunger hormones. ${ }^{44}$ Conversely, sugar has been shown to reduce $\mathrm{PYY}^{45}$ and to increase hyperphagia and hyperinsulinaemia in animal studies. ${ }^{46}$ One proposed explanation for increased food intake could be the activation of the 'reward system' by foods high in sugar and fat and mediated by endogenous opioids, dopamine and serotonin. ${ }^{47}$ Stimulating the reward system results in a sense of gratification that drives overeating. This, coupled with disrupted hunger-satiety signals, may cause an imbalance in energy homoeostasis by which energy intake exceeds energy expenditure.

Alternatively, the pregnant women in our study could have intentionally consumed a high-protein/lowcarbohydrate diet to avoid excessive GWG. Such a diet may increase adherence given a resemblance to a more typical Western-type diet rich in protein from, for example, meat, eggs and fish, and due to increased satiety. Avoiding sweets and added sugar on a higher protein diet may also be more manageable than following, for example, a low-fat diet consisting primarily of fruits and vegetables. In our data, we were unable to separate out the pregnant women who were intentionally eating a high-protein/low-carbohydrate diet and can therefore only speculate on any behavioural explanations of our results.

Our study had some limitations. We assessed diet around the 25th week of gestation for the four previous weeks. The assessment can therefore be considered cross-sectional in relation to the ongoing GWG and question the temporality of the association. However, relative stability in intake across trimesters has also been observed, ${ }^{48}$ and similar or even later time points of dietary assessment have been used by prior studies on GWG. ${ }^{7}{ }^{21}$ We used self-reported dietary and outcome data. FFQ tends to perform worse in estimating absolute intake compared with other dietary assessment tools, but captures habitual dietary intake and does well in ranking individuals according to intake habits. Our FFQ has been validated in 88 women participating in the DNBC and showed good correlation for protein between the FFQ and food diaries. ${ }^{30}$ We would expect random measurement error in estimating the exposure and an underestimation of the effect estimates, at least among normal weight and overweight women. We suspect that obese women, being more conscious of their weight gain, may have systematically under-reported their intake. This would explain the reversed associations we observed for this subgroup in the stratified analyses. In this analysis, we employed a macronutrient substitution model which requires isocaloric conditions. While caloric intake may increase with the progression of the pregnancy, this study calculated dietary intake for 1 month only, and hence we would not expect a substantial change in energy during this short time period.

Self-reported weight was used to calculate GWG. While self-reported weight, including pre-pregnancy weight reported by pregnant women, has been found to be valid, overweight and obese women tend to underestimate their weight. ${ }^{50-52}$ We therefore stratified on prepregnancy BMI and found similar associations for normal weight and overweight women. Bias may have still occurred in the obese group. Under-reporting of GWG only would lead to reverse associations in this group. However, the exact level and direction of bias would depend on the extent of under-reporting of weight at both weeks 12 and 30 of gestation as well as under-reporting on the exposure. We cannot exclude the possibility that some of the weight gain was due to fluid retention that occurs during pregnancy. However, it is likely that any fluid retention would be equally distributed across the intakes of the protein-to-carbohydrate ratio and added sugar, as the diet composition has not been implicated in fluid retention as long as a minimal protein intake is ensured. Only $1.3 \%$ of women in our cohort had protein intakes below $10 \% \mathrm{E}$.

The primary strengths of this study are the large study population, detailed dietary assessment and extensive data on covariates. Stratifying on BMI allowed us to elucidate effect differences across population groups, which is important for designing future trials and in making targeted recommendations to pregnant women.

In a prospective cohort of over 46000 pregnant women, we found that a high $\mathrm{P} / \mathrm{C}$ ratio and low intake of added sugar and selected high GI foods decreased GWG in both normal weight and overweight women. Results were non-significant and in the opposite direction for obese women, which may have been due to reverse causation. Therefore, dietary predictors of GWG in this subgroup need to be specifically examined in future studies. We were unable to distinguish between the effect of the $\mathrm{P} / \mathrm{C}$ ratio or added sugar on $\mathrm{GWG}$, and controlled trials are needed to tease apart these effects.

\footnotetext{
Author affiliations

${ }^{1}$ Centre for Fetal Programming, Department of Epidemiology Research, Statens Serum Institute, Copenhagen, Denmark

${ }^{2}$ Faculty of Food Science and Nutrition, School of Health Sciences, University of Iceland, Reykjavik, Iceland

${ }^{3}$ Unit for Nutrition Research, Landspitali University Hospital, Reykjavik, Iceland ${ }^{4}$ Department of Nutrition, Exercise and Sports, Faculty of Science, University of Copenhagen, Copenhagen, Denmark

${ }^{5}$ Department of Nutrition, Harvard T.H. Chan School of Public Health, Boston, Massachusetts, USA
} 
Contributors AA, TIH and SFO were involved in study concept and design. EM and TIH prepared the data and conducted the statistical analyses. EM drafted the manuscript. EM, TIH, AA and SFO were involved in interpretation of the data, contributed critical advice and revisions of the manuscript with important intellectual content. SFO was involved in funding. EM and SFO were involved in acquisition of data and take responsibility for the entire contents of the manuscript. All authors had full access to study data and approved the final version of the manuscript.

Funding This study was supported by a grant from the Nordea Foundation Denmark, the Danish Council for Strategic Research (Centre for Fetal Programming, 09-067124); the Danish Council for Independent Research | Medical Sciences, the Danish Agency for Science, Technology and Innovation (09-063410); the Lundbeck foundation (R13-A907); and the European Union (EU) Integrated Research Project EARNEST (FO0D-CT-2005-007036). The Danish National Birth Cohort has been financed by the March of Dimes Birth Defects Foundation, the Danish Heart Association, the Danish Medical Research Council, Sygekassernes Helsefond, the Danish National Research Foundation, the Danish Pharmaceutical Association, the Ministry of Health, the National Board of Health and the Statens Serum Institut.

Competing interests All authors have completed the Unified Competing Interests form at http://www.icmje.org/coi_disclosure.pdf (available on request from the corresponding author) and declare: AA reports personal fees from Global Dairy Platform, USA, Jenny Craig, USA, McCain Foods Limited, USA, and from McDonald's, USA, outside the submitted work.

Ethics approval The Regional Scientific Ethics Committee for the municipalities of Copenhagen and Frederiksberg approved all study protocols, and all procedures were in accordance with the Declaration of Helsinki.

Provenance and peer review Not commissioned; externally peer reviewed.

Data sharing statement No additional data are available.

Open Access This is an Open Access article distributed in accordance with the Creative Commons Attribution Non Commercial (CC BY-NC 4.0) license, which permits others to distribute, remix, adapt, build upon this work noncommercially, and license their derivative works on different terms, provided the original work is properly cited and the use is non-commercial. See: http:// creativecommons.org/licenses/by-nc/4.0/

\section{REFERENCES}

1. Hedderson MM, Gunderson EP, Ferrara A. Gestational weight gain and risk of gestational diabetes mellitus. Obstet Gynecol 2010;115:597-604

2. Thorsdottir I, Torfadottir JE, Birgisdottir BE, et al. Weight gain in women of normal weight before pregnancy: complications in pregnancy or delivery and birth outcome. Obstet Gynecol 2002; 99(5 Pt 1):799-806.

3. Johnson JW, Longmate JA, Frentzen B. Excessive maternal weight and pregnancy outcome. Am J Obstet Gynecol 1992;167:353-70; discussion 70-2.

4. Oken E, Rifas-Shiman SL, Field AE, et al. Maternal gestational weight gain and offspring weight in adolescence. Obstet Gynecol 2008;112:999-1006.

5. Stuebe AM, Forman MR, Michels KB. Maternal-recalled gestational weight gain, pre-pregnancy body mass index, and obesity in the daughter. Int J Obes (Lond) 2009;33:743-52.

6. Haberg SE, London SJ, Stigum H, et al. Folic acid supplements in pregnancy and early childhood respiratory health. Arch Dis Child 2009;94:180-4

7. Deierlein AL, Siega-Riz AM, Herring A. Dietary energy density but not glycemic load is associated with gestational weight gain. $A m$ Clin Nutr 2008;88:693-9.

8. Olafsdottir AS, Skuladottir GV, Thorsdottir I, et al. Maternal diet in early and late pregnancy in relation to weight gain. Int $J$ Obes (Lond) 2006;30:492-9.

9. Stuebe AM, Oken E, Gillman MW. Associations of diet and physical activity during pregnancy with risk for excessive gestational weight gain. Am J Obstet Gynecol 2009;201:58 e1-8.

10. Gray-Donald K, Robinson $\mathrm{E}$, Collier $\mathrm{A}$, et al. Intervening to reduce weight gain in pregnancy and gestational diabetes mellitus in Cree communities: an evaluation. CMAJ 2000;163:1247-51.

11. Guelinckx I, Devlieger R, Mullie P, et al. Effect of lifestyle intervention on dietary habits, physical activity, and gestational weight gain in obese pregnant women: a randomized controlled trial. Am J Clin Nutr 2010;91:373-80.

12. Jeffries K, Shub A, Walker SP, et al. Reducing excessive weight gain in pregnancy: a randomised controlled trial. Med J Aust 2009;191:429-33.

13. Kinnunen TI, Pasanen $M$, Aittasalo $M$, et al. Preventing excessive weight gain during pregnancy-a controlled trial in primary health care. Eur J Clin Nutr 2007;61:884-91.

14. Polley BA, Wing RR, Sims CJ. Randomized controlled trial to prevent excessive weight gain in pregnant women. Int $J$ Obes Relat Metab Disord 2002;26:1494-502.

15. Asbee SM, Jenkins TR, Butler JR, et al. Preventing excessive weight gain during pregnancy through dietary and lifestyle counseling: a randomized controlled trial. Obstet Gynecol 2009; 113(2 Pt 1):305-12.

16. Phelan S, Phipps MG, Abrams B, et al. Randomized trial of a behavioral intervention to prevent excessive gestational weight gain: the Fit for Delivery Study. Am J Clin Nutr 2011;93:772-9.

17. Claesson IM, Sydsjo G, Brynhildsen J, et al. Weight gain restriction for obese pregnant women: a case-control intervention study. BJOG 2008;115:44-50.

18. Shirazian T, Monteith S, Friedman F, et al. Lifestyle modification program decreases pregnancy weight gain in obese women. $A m$ Perinatol 2010;27:411-14.

19. Wolff $\mathrm{S}$, Legarth J, Vangsgaard $\mathrm{K}$, et al. A randomized trial of the effects of dietary counseling on gestational weight gain and glucose metabolism in obese pregnant women. Int $J$ Obes (Lond) 2008;32:495-501.

20. Olson CM, Strawderman MS, Reed RG. Efficacy of an intervention to prevent excessive gestational weight gain. Am J Obstet Gynecol 2004;191:530-6.

21. Lagiou P, Tamimi RM, Mucci LA, et al. Diet during pregnancy in relation to maternal weight gain and birth size. Eur J Clin Nutr 2004:58:231-7.

22. $\mathrm{Hu} \mathrm{T}$, Mills $\mathrm{KT}$, Yao L, et al. Effects of low-carbohydrate diets versus low-fat diets on metabolic risk factors: a meta-analysis of randomized controlled clinical trials. Am J Epidemiol 2012;176(Supp 7):S44-54

23. Krieger JW, Sitren HS, Daniels MJ, et al. Effects of variation in protein and carbohydrate intake on body mass and composition during energy restriction: a meta-regression 1. Am J Clin Nutr 2006;83:260-74.

24. Larsen TM, Dalskov SM, van Baak M, et al. Diets with high or low protein content and glycemic index for weight-loss maintenance. N Engl J Med 2010;363:2102-13.

25. Wycherley TP, Moran LJ, Clifton PM, et al. Effects of energy-restricted high-protein, low-fat compared with standard-protein, low-fat diets: a meta-analysis of randomized controlled trials. Am J Clin Nutr 2012;96:1281-98.

26. Clifton PM, Condo D, Keogh JB. Long term weight maintenance after advice to consume low carbohydrate, higher protein diets-a systematic review and meta analysis. Nutr Metab Cardiovasc Dis 2014;24:224-35.

27. Kramer MS, Kakuma R. Energy and protein intake in pregnancy. Cochrane Database Syst Rev 2003;(4):CD000032.

28. Olsen SF, Mikkelsen TB, Knudsen VK, et al. Data collected on maternal dietary exposures in the Danish National Birth Cohort Paediatr Perinat Epidemiol 2007;21:76-86.

28a Olsen J, Melbye M, Olsen SF, et al. The Danish National Birth Cohort-its background, structure and aim. Scand J Public Health 2001;29:300-7.

29. Mikkelsen TB, Olsen SF, Rasmussen SE, et al. Relative validity of fruit and vegetable intake estimated by the food frequency questionnaire used in the Danish National Birth Cohort. Scand $J$ Public Health 2007;35:172-9.

30. Mikkelsen TB, Osler M, Olsen SF. Validity of protein, retinol, folic acid and n-3 fatty acid intakes estimated from the food-frequency questionnaire used in the Danish National Birth Cohort. Public Health Nutr 2006:9:771-8.

31. Willett WC, Howe GR, Kushi LH. Adjustment for total energy intake in epidemiologic studies. Am J Clin Nutr 1997;65(4 Suppl): 1220S-8S; discussion 29S-31S.

32. Slavin JL. Dietary fiber and body weight. Nutrition 2005;21:411-18.

33. Abargouei AS, Janghorbani M, Salehi-Marzijarani M, et al. Effect of dairy consumption on weight and body composition in adults: a systematic review and meta-analysis of randomized controlled clinical trials. Int J Obes (Lond) 2012;36:1485-93.

34. Bender N, Portmann M, Heg Z, et al. Fish or n3-PUFA intake and body composition: a systematic review and meta-analysis. Obes Rev 2014;15:657-65. 
35. Cogswell ME, Serdula MK, Hungerford DW, et al. Gestational weight gain among average-weight and overweight women-what is excessive? Am J Obstet Gynecol 1995; 172(2 Pt 1):705-12.

36. Chu SY, Callaghan WM, Bish CL, et al. Gestational weight gain by body mass index among US women delivering live births, 20042005: fueling future obesity. Am J Obstet Gynecol 2009;200:271. e1-7.

37. Sacks FM, Bray GA, Carey VJ, et al. Comparison of weight-loss diets with different compositions of fat, protein, and carbohydrates. N Engl J Med 2009;360:859-73.

38. IOM (Institute of Medicine) and NRC (National Research Council). Weight gain during pregnancy: reexamining the guidelines. Washington DC: The National Academies Press, 2009.

39. Olsen SF, Halldorsson TI, Willett WC, et al. Milk consumption during pregnancy is associated with increased infant size at birth: prospective cohort study. Am J Clin Nutr 2007;86:1104-10.

40. Maslova $\mathrm{E}$, Rytter $\mathrm{D}$, Bech $\mathrm{BH}$, et al. Maternal protein intake during pregnancy and offspring overweight 20 y later. Am J Clin Nutr 2014; 100:1139-48.

41. Knudsen VK, Heitmann BL, Halldorsson $\mathrm{Tl}$, et al. Maternal dietary glycaemic load during pregnancy and gestational weight gain, birth weight and postpartum weight retention: a study within the Danish National Birth Cohort. Br J Nutr 2013;109:1471-8.

42. Paddon-Jones D, Westman E, Mattes RD, et al. Protein, weight management, and satiety. Am J Clin Nutr 2008;87:1558S-61S.
43. Belza A, Ritz C, Sorensen MQ, et al. Contribution of gastroenteropancreatic appetite hormones to protein-induced satiety. Am J Clin Nutr 2013;97:980-9.

44. Bowen J, Noakes M, Clifton PM. Appetite hormones and energy intake in obese men after consumption of fructose, glucose and whey protein beverages. Int J Obes (Lond) 2007;31:1696-703.

45. Lindqvist A, Baelemans A, Erlanson-Albertsson C. Effects of sucrose, glucose and fructose on peripheral and central appetite signals. Regul Pept 2008;150:26-32.

46. Kaga $\mathrm{T}$, Inui $\mathrm{A}$, Okita $\mathrm{M}$, et al. Modest overexpression of neuropeptide $Y$ in the brain leads to obesity after high-sucrose feeding. Diabetes 2001;50:1206-10.

47. Erlanson-Albertsson C. How palatable food disrupts appetite regulation. Basic Clin Pharmacol Toxicol 2005;97:61-73.

48. Cuco G, Fernandez-Ballart J, Sala J, et al. Dietary patterns and associated lifestyles in preconception, pregnancy and postpartum. Eur J Clin Nutr 2006;60:364-71.

49. Rifas-Shiman SL, Rich-Edwards JW, Willett WC, et al. Changes in dietary intake from the first to the second trimester of pregnancy. Paediatr Perinat Epidemiol 2006;20:35-42.

50. Brunner Huber LR. Validity of self-reported height and weight in women of reproductive age. Matern Child Health J 2007;11:137-44.

51. Oken E, Taveras EM, Kleinman KP, et al. Gestational weight gain and child adiposity at age 3 years. Am J Obstet Gynecol 2007;196:322 e1-8.

52. Rowland ML. Self-reported weight and height. Am J Clin Nutr 1990;52:1125-33. 